\title{
Letter to the editor about the article "Different surgical outcomes in a patient with bilateral atypical femoral fracture related to bisphosphonate use with or without teriparatide treatment"
}

\author{
C.-H. Kim ${ }^{1}$ - J. W. Kim² ${ }^{2}$ \\ Received: 13 November 2019 / Accepted: 17 February 2020 / Published online: 6 March 2020 \\ (C) International Osteoporosis Foundation and National Osteoporosis Foundation 2020
}

Dear Editor,

We recently read with interest the article titled, "Different surgical outcomes in a patient with bilateral atypical femoral fracture related to bisphosphonate use with or without teriparatide treatment" [1]. The authors mentioned that although the same surgical procedure was performed, its outcomes were different with or without teriparatide. However, we have a genuine concern about this case report.

We are doubtful about the success of the surgical treatment because of the discordance in the fracture reduction between both hips. Subtrochanteric femoral fractures have higher nonunion rates compared with other anatomical regions besides atypical femur fracture (AFF) [2]. Risk factors for nonunion include varus malreduction, residual displacement after reduction, lack of medial cortical support, and bisphosphonateassociated fractures. In addition, many studies advocate the importance of fracture reduction for healing of AFFs [3-5]. They emphasize that varus malreduction could cause either a nonunion fracture or a delay in AFF treatment. Figure 1 of this case report shows definite varus malreduction and residual displacement, and we are curious about whether the left hip achieved satisfactory reduction and fixation postoperatively. If not, the outcomes would be poor regardless of teriparatide use.

We therefore seek clarification of the surgical results achieved and believe that the explanation provided by the authors is incomplete. With the ongoing debate on effects of teriparatide after surgical fixation of AFF, we worry that this

J. W. Kim

bakpaker@hanmail.net

1 Department of Orthopedic Surgery, Gachon University Gil Medical Center, 21, Namdong-daero 774 beon-gil, Namdong-gu, Incheon 21565, Republic of Korea

2 Department of Orthopedic Surgery, Asan Medical Center, University of Ulsan, College of Medicine, 88 Olympic-ro 43-gil, Songpa-gu, Seoul 05505, Republic of Korea report would unnecessarily mislead people. We hope that the authors address the points presented, as the overall discussion of the presented points will only serve to benefit the research community at large.

\section{Compliance with ethical standards}

Conflict of interest None.

\section{References}

1. Zhang HY, Weng HL, Li M, Zhang J (2019) Different surgical outcomes in a patient with bilateral atypical femoral fracture related to bisphosphonate use with or without teriparatide treatment. Osteoporos Int 30(11):2349-2354

2. Krappinger D, Wolf B, Dammerer D, Thaler M, Schwendinger P, Lindtner RA (2019) Risk factors for nonunion after intramedullary nailing of subtrochanteric femoral fractures. Arch Orthop Trauma Surg 139(6):769-777

3. Cho JW, Oh CW, Leung F, Park KC, Wong M, Kwek E, Kim HJ, Oh JK (2017) Healing of atypical subtrochanteric femur fractures after cephalomedullary nailing: which factors predict union? J Orthop Trauma 31(3):138-145

4. Egol KA, Park JH, Rosenberg ZS, Peck V, Tejwani NC (2014) Healing delayed but generally reliable after bisphosphonateassociated complete femur fractures treated with IM nails. Clin Orthop 472(9):2728-2734

5. Lim HS, Kim CK, Park YS, Moon YW, Lim SJ, Kim SM (2016) Factors associated with increased healing time in complete femoral fractures after long-term bisphosphonate therapy. J Bone Joint Surg Am 98(23):1978-1987

Publisher's note Springer Nature remains neutral with regard to jurisdictional claims in published maps and institutional affiliations. 